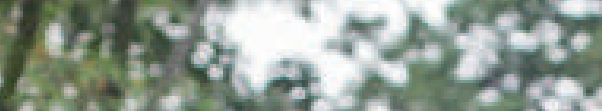

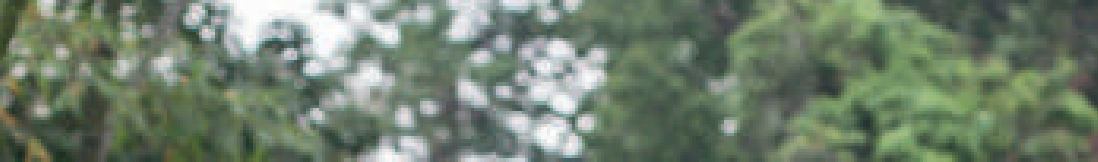

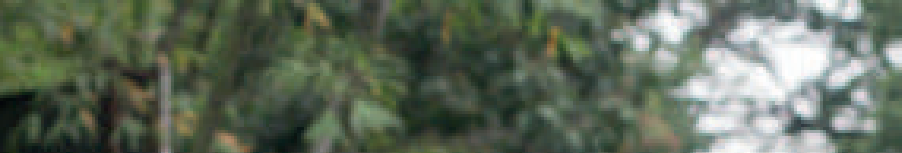

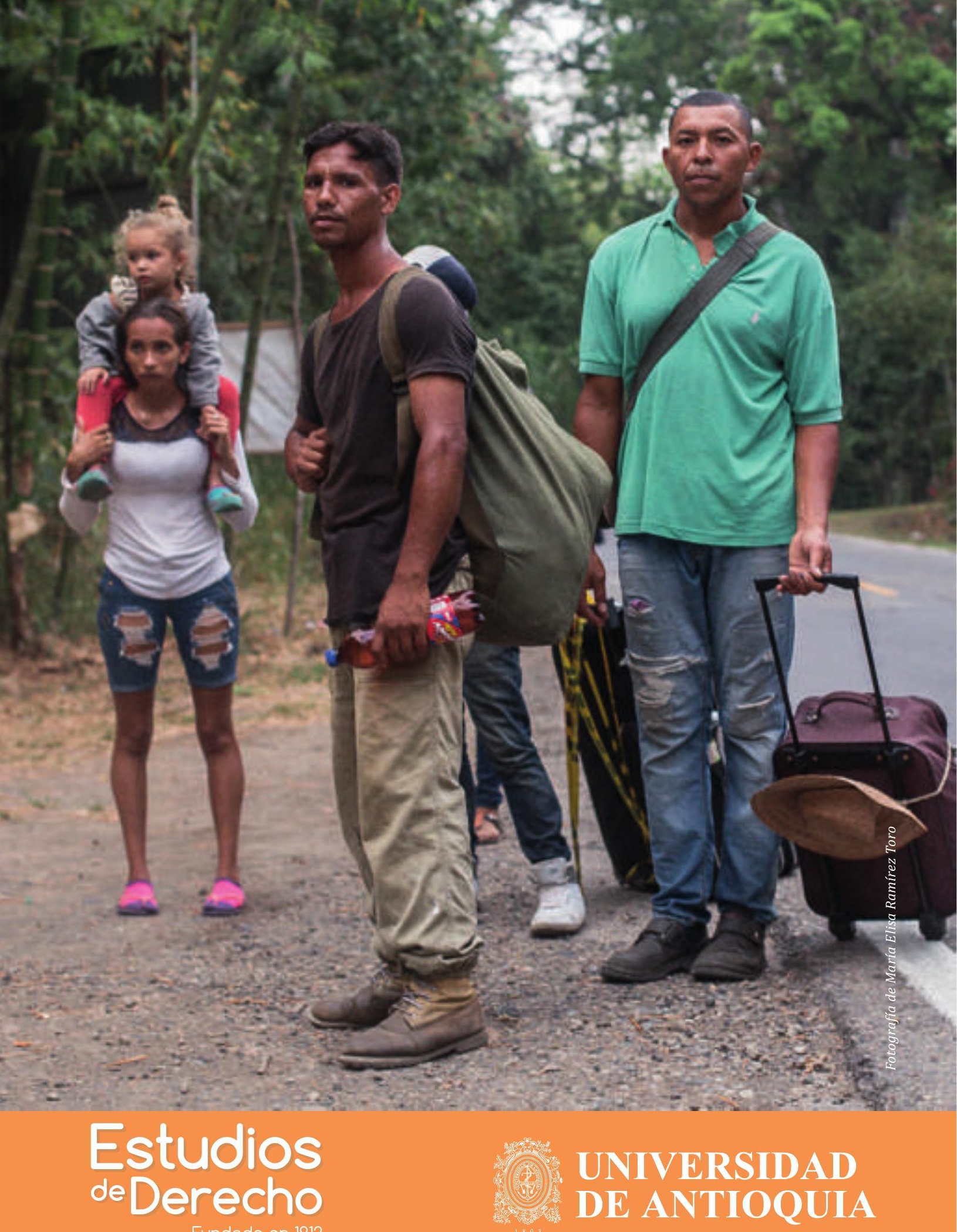




\title{
Programas de Retorno Voluntario. El caso chileno*
}

\section{Marcos Andrade Moreno ${ }^{* *}$}

\section{Resumen}

En el artículo se busca determinar la naturaleza jurídica del Plan Humanitario de Regreso Ordenado de Extranjeros (PHRO). Para ello, se reconstruye la práctica jurídica de expulsión de extranjeros en Chile, la que se compone de dos regímenes: uno penal y otro administrativo. Se muestran las diferencias y semejanzas de dichos regímenes y se les compara con el PHRO. Este ejercicio muestra que, a pesar de las diferencias, el PHRO alcanza los mismos efectos que los regímenes penal y administrativo de expulsiones, pero sin el control de la efectiva protección a los Derechos Humanos que ofrecen los Tribunales. Desde este punto de vista, el PHRO sería una especie expulsión velada, ya que consigue los mismos efectos jurídicos que los regímenes de expulsión, apelando a dudosas consideraciones humanitarias y basado en una "lógica del apartamiento".

Palabras clave: plan de retorno voluntario; expulsión de extranjeros; sanción administrativa; pena, lógica del apartamiento.

\section{Voluntary return programs. The Chilean case}

\begin{abstract}
The article seeks to determine the legal nature of the Humanitarian Plan for the Organized Return of Foreigners (PHRO, for its acronym in Spanish). To do this, the legal practice of expulsion of foreigners in Chile is reconstructed. This practice is composed of two regimes: one of them is criminal and the other is administrative. The differences and similarities of these regimes are shown and compared to the PHRO. This exercise demonstrates that, despite the differences, the PHRO has the same effects as the criminal and administrative expulsion regimes, but without the oversight of the effective protection of Human Rights provided by the Courts. From this point of view, the PHRO would be a veiled species of expulsion, since it has the same legal effects as the expulsion regimes, appealing to doubtful humanitarian considerations and based on a "logic of isolation".
\end{abstract}

Keywords: voluntary return plan, expulsion of foreigners; administrative penalti; penalti; logic of isolation.

\section{Programas de retorno voluntário. 0 exemplo chileno}

\section{Resumo}

O artigo busca identificar a natureza jurídica do Planejamento Humanitário de Retorno de Exilados (PHRO). Para isto, é refeita a prática legal da expelida de expatriados no Chile, constituída por dois regimes: um criminoso e um administrativo. As diferenças e semelhanças naqueles regimes são apresentadas num versus comparativo ao PHRO. Esta metodologia demostra que, embora existam diferenças, o PHRO atinge os mesmos resultados que os regimes criminais e administrativos de expulsão, porém sem nenhuma controladoria nem salvaguarda eficaz dos direitos humanos oferecida pelas varas tribunais. Desde este ponto de vista, o PHRO seria uma espécie segreda de expulsão, uma vez que atinge iguais resultados legais desses regimes de expulsão, apelando a razões humanitárias duvidosas e afincadas nessa "lógica do afastamento".

Palavras-chave: planejamento do retorno voluntário; expelida dos expatriados; penalidade administrativa; penalidade; lógica do afastamento.

* Artículo de reflexión derivado de investigación. Proyecto de Investigación Postdoctoral (POP) BES-2014-068127 “Normas alterativas de derechos como fundamento de la flexibilidad normativa", Área de Filosofía del Derecho, Universitat Pompeu Fabra. Proyecto finan- ciado por el Programa Estatal de Promoción del Talento y su Empleabilidad en I+D+i Subprograma Estatal de Formación, España. Tutor: Dr. José Juan Moreso; Investigador responsable: Dr. Marcos Andrade Moreno. Duración 2017-2018.

** Profesor Auxiliar, Facultad de Ciencias Jurídicas y Sociales, Universidad Austral de Chile, Chile. Abogado y Magíster en Derecho, Universidad de Chile; Doctor en Derecho, Universitat Pompeu Fabra. Instituto de Derecho Público y Ciencias del Derecho UACh. Correo electrónico: marcos.andrade@uach.cl. ORCID: https://orcid.org/0000-0002-2796-207X

Cómo citar este artículo: Andrade, M. (2020). Programas de Retorno Voluntario. El caso chileno. Estudios de Derecho, 77 (169), 87-117 


\section{Programas de Retorno Voluntario. El caso chileno}

\section{Introducción}

En la década de los noventa, con el retorno a la democracia en Chile, la migración intrarregional comenzó a incrementarse sostenidamente (Revista Colecciones Jurídicas: "Migrantes", 2019). En la última década Chile ha visto crecer dicha migración de manera sostenida (Martínez y Orrego, 2016), siendo últimamente, entre abril de 2017 y diciembre de 2018, dos grupos regionales los que destacan: los venezolanos y los haitianos (Instituto Nacional de Estadística [INE], 2018; Instituto Nacional de Estadística [INE] y Departamento de Extranjería y Migración [DEM], 2019). Por ejemplo, según datos de la Policía de Investigaciones de Chile (PDI), en 2017 un total de 424.739 turistas continuaron permaneciendo en Chile más allá del plazo legal. En ese mismo año, entraron a Chile como turistas 111.761 haitianos, de los cuales solo 2.381 salieron de Chile y 132.492 venezolanos, de los cuales solo 34.118 dejaron de Chile; lo que representa, respectivamente, el 25,74 $\%$ y 23,16 \% del total de turistas que siguieron permaneciendo en Chile.

Con la instalación del nuevo gobierno, en marzo de 2018, se adoptaron diversas medidas administrativas sobre migración, algunas de ellas específicas para los grupos de migrantes mencionados, y semejantes a medidas adoptadas en otros países de la región ${ }^{1}$ : a) Proyecto de Ley de Migración y Extranjería (Boletín №8.970-06), que busca reemplazar regulación vigente del Decreto Ley 1094, en actual discusión en el parlamento; b) Proceso Extraordinario de Regularización; c) se eliminó la posibilidad de que los turistas puedan cambiar su calidad migratoria a residente estando en Chile (mediante visado de residencia temporaria); d) Visa Temporaria de Oportunidades y Visa Temporaria de Orientación Nacional e Internacional; e) Visado Consular de Turismo Simple para ciudadanos haitianos y recientemente para ciudadanos venezolanos; f) Visa de Responsabilidad Democrática para ciudadanos venezolanos; g) Sistema de Reserva de Horas en 
aplicación web; g) Plan humanitario de regreso ordenado para extranjeros (en adelante, $\mathrm{PHRO})^{2}$.

La medida que me propongo analizar aquí es el PHRO, establecido por el gobierno chileno en octubre de 2018, con el propósito de regular el "regreso ordenado al país de origen de ciudadanos extranjeros"3.

¿Cuál es el carácter jurídico del PHRO? El presente trabajo busca dos objetivos. El primero, mostrar que, si bien el PHRO es un plan de retorno voluntario, no es un plan humanitario desde la perspectiva del derecho internacional de los derechos humanos. El segundo, que el PHRO se parece bastante a una forma encubierta de deportación masiva y selectiva de extranjeros, si se la analiza a la luz de la práctica jurídica de expulsión de extranjeros que contempla el sistema jurídico chileno ${ }^{4}$.

En una primera aproximación, la expulsión de extranjeros puede entenderse "como una salida coactiva del territorio nacional acompañada de la prohibición temporal de entrada en él" (Muñoz Ruiz, 2014, p. 05:7). Conforme al derecho internacional de los derechos humanos ${ }^{5}$, las regulaciones de derecho interno en materia de expulsiones deben establecerse considerando ciertos estándares mínimos ${ }^{6}$. Es dicha práctica jurídica de las expulsiones contemplada en el derecho chileno,

2 Minuta Reforma Migratoria y Política Nacional de Migraciones y Extranjería (2018).

3 Resolución Exenta №5744 de 2018. Cabe destacar que, en el derecho chileno, las Resoluciones Exentas no pasan por el trámite de toma de razón de la Contraloría General de la República, órgano que revisa la legalidad de los actos de la administración.

4 Aquí, uso la noción de práctica jurídica en un sentido laxo, como una especie de práctica social compleja, que configura un cuerpo jurídico adquirido (acquis), producto de la interacción entre el material legislativo y su interpretación y aplicación en decisiones administrativas y judiciales. Esto implica que, dado que "el derecho es una empresa normativa [...] la distinción entre teoría y práctica jurídica es a lo sumo una cuestión de grado" (Sunstein, 1995, p. 267). Dicha gradualidad se expresa en el tipo de teoría acerca de la práctica social que llamamos derecho que se busca desarrollar. Véase Bix (2006).

5 La Convención Americana sobre Derechos Humanos, San José, Costa Rica (7 al 22 de noviembre de 1969), establece en su artículo 22 el Derecho de Circulación y de Residencia, señalando específicamente que: los extranjeros solo podrán ser expulsados "en cumplimiento de una decisión adoptada conforme a la ley" (22.6); que "en ningún caso el extranjero puede ser expulsado o devuelto a otro país, sea o no de origen, donde su derecho a la vida o a la libertad personal está en riesgo de violación a causa de raza, nacionalidad, religión, condición social o de sus opiniones políticas" (22.8); y que está "prohibida la expulsión colectiva de extranjeros" (22.9). La Convención internacional sobre la protección de los derechos de todos los trabajadores migratorios y de sus familiares, Nueva York (18 de diciembre de 1990), establece en el artículo 22 la prohibición de expulsión colectiva y garantías procedimentales en los procesos de expulsión individual; y en el artículo 23, la protección consular. Esto, incluso, se aplica en el caso de los trabajadores en situación irregular, como señala Observación General NN2 del Comité de Protección de los Derechos de Todos los Trabajadores Migratorios y de sus Familiares (28/08/2013), parágrafos 50 y 51.

6 Los estándares internacionales de derechos humanos no prohíben a los Estados regular el ingreso, salida, permanencia o salida coactiva de extranjeros del territorio del Estado, sino que establecen límites a tales regulaciones en dos aspectos claves. Primero, "la expulsión no debe ir acompañada de daños, vejaciones o sufrimientos innecesarios, que pudieran considerarse inhumanos". Segundo, "el Estado debe articular y conceder un trámite de audiencia y un derecho de recurso en favor del extranjero" (Díaz, 2016, p. 197). Es decir, en materia de expulsión de extranjeros, se refieren tanto a sus causales como al debido proceso. 
valorada a la luz de estos límites, la que será reconstruida aquí como parámetro de comparación del PHRO.

Con este fin, se requiere mostrar, en primer lugar, qué se entiende por un plan de retorno voluntario y qué justifica su carácter de humanitario por el Derecho Internacional, a fin de mostrar el carácter problemático de calificar al PHRO como tal. En segundo lugar, se precisa reconstruir la práctica jurídica de expulsión de extranjeros, para lo cual se debe tratar conceptualmente de manera integrada los regímenes penal y administrativo de expulsión de extranjeros que contempla el sistema jurídico chileno, a fin de mostrar sus similitudes y diferencias, ya que, solo a partir de ellas, es posible apreciar por qué es problemática la naturaleza jurídica del PHRO, el que, a pesar de ser un plan voluntario y aparentemente beneficioso para el extranjero, posee en realidad los mismos efectos jurídicos que los regímenes de expulsión.

En lo sucesivo, se tratará de explicar las razones que subyacen a estas afirmaciones. Para lo cual, en la sección segunda se mostrará por qué al PHRO no corresponde llamarlo un plan humanitario. En la sección tercera, se describirán a grandes rasgos el régimen penal y administrativo de expulsión de extranjeros. En la sección cuarta se compararán dichos regímenes con la PHRO y se presentarán las conclusiones.

\section{Plan de retorno voluntario y su calificativo de "humanitario"}

Son varias las razones que expresa la Resolución Exenta que estableció el PHRO, justificando su adopción: 1) La solicitud de la propia comunidad, mencionando "a nacionales haitianos" (letra a y b); 2) Aludiendo a que los retornos voluntarios asistidos y estrategias de reintegración son parte de la perspectiva global de gobernanza migratoria que promueve Organización Internacional para las Migraciones (OIM) (letra c); 3) El interés nacional en "dotar al país de una migración ordenada, segura y regular" (letra d); 4) Obligación de cooperar en regreso ordenado de trabajadores migratorios y sus familiares al Estado de origen, según dispone la Convención sobre los trabajadores migratorios (letra e) ${ }^{7}$.

Entre estas razones, la principal es la que se señala en la letra d):

Se hace indispensable atender a la situación planteada por las comunidades migrantes de aquellas personas que se encuentran en situación de vulnerabilidad, por no haber logrado una eficaz integración, sustentabilidad o regularidad en el país, por razones

$7 \quad$ Resolución Exenta №5744 de 2018. 
laborales, idiomáticas, socioculturales o por no poder cumplir con los requisitos establecidos para acceder a los diferentes medios de regularización ordinaria o extraordinaria. (Ministerio del Interior y Seguridad Pública y la Subsecretaría del Interior, 2018)

En este sentido, el PHRO se enmarcaría en una política de retorno de migrantes $^{8}$, a través de la implementación de un plan de retorno voluntario asistido. Estos planes se entienden como "la provisión de asistencia para el retorno voluntario de las personas que se acogen al mismo", es decir, "es una acepción restringida del término retorno voluntario” (Sánchez \& Fernández, 2010, pp. 138-139). Esto, porque obviamente un migrante puede retornar por cuenta propia a su país de origen, sin asistencia de organismos públicos o privados.

Estos programas son promovidos por diversos organismos y foros internacionales, especialmente la $\mathrm{OIM}^{9}$, y se dirigen tanto hacia migrantes con residencia en vigor o en situación de irregularidad. Aunque no es el propósito de este trabajo, se deben mencionar brevemente las formas en que teóricamente se ha abordado el fenómeno de retorno de migrantes a sus países de origen.

En términos generales, según muestra la evidencia empírica (para el caso español), en la decisión de retorno al país de origen "sobresalen tres factores determinantes: la situación laboral, familiar y legal en el país de acogida" o destino (Resino, Jiménez y Arranz, 2018, p. 110).

Sobre lo anterior, hay dos conjuntos de teorías que buscan dar cuenta de dicho fenómeno. En primer lugar, las teorías reduccionistas, que circunscriben dicho fenómeno a parámetros económicos, ya sea, al análisis costo-beneficio, al ciclo de vida laboral o la imperfección de los mercados, todos las cuales explican el retorno al país de origen en términos del fracaso económico del migrante en el país de acogida o destino, basándose "en la idea de un hombre libre que escoge la alternativa que más le conviene desde un punto de vista de beneficio económico" (Resino et al., 2018, p. 94).

El término migrante es definido por la OIM (2018) como: "Cualquier persona que se mude o se haya mudado a través de una frontera internacional o dentro de un Estado fuera de su lugar de residencia habitual, independientemente de (1) el estado legal de la persona; (2) si el movimiento es voluntario o involuntario; (3) cuáles son las causas del movimiento; o (4) cuál es la duración de la estadía" Organización Internacional para las Migraciones (p. 1). Nótese que desde la perspectiva del derecho chileno el migrante siempre es extranjero, como señala el artículo 5 del Decreto con Fuerza de Ley №69 de 1953, que establece: "Inmigrante es el extranjero que ingresa al país con el objeto de radicarse, trabajar y cumplir las disposiciones del presente Decreto con Fuerza de Ley". Por ello, para el ordenamiento jurídico chileno, migrante y extranjeros son términos jurídicos equivalentes, razón por la cual el PHRO es parte de una política estatal dirigida a un colectivo específico: extranjeros que se encuentren en Chile bajo ciertas condiciones.

9 Recientemente, la OIM aprobó un marco general para los programas de retorno asistido, el que contempla una serie de principios generales que dichos programas deben cumplir: "voluntariedad, respuesta centrada en el migrante, seguridad, sustentabilidad de la reintegración, confidencialidad, diálogo institucional y asociatividad y programas basados en evidencia” Organización Internacional para las Migraciones (2018, p. 7). 
En segundo lugar, las teorías no reduccionistas, que reconocen la complejidad del fenómeno migratorio, ya sea, el enfoque transnacional, que entiende a la migración como un proceso "complejo y sistémico, que incluye relaciones económicas, sociales y culturales entre las sociedades de origen y las de destino, mediadas por un constante intercambio de recursos, dinero, bienes, ideas, información y valores" (Resino et al., 2018, p. 96); o la circularidad migratoria, que pone énfasis en el movimiento incesante de migrantes entre distintos países de origen y destino, donde el retorno "es una etapa más en un proceso que lleva al migrante a un nuevo destino de emigración" o bien retorna "al reconsiderar la vuelta al país de inmigración como una opción mejor" (Resino et al., 2018, p. 96).

Por otra parte, más allá de la discusión anterior, el tipo de asistencia que los planes de retorno voluntario contemplan, generalmente, varía según sea el estatus migratorio de sus beneficiarios. En el caso de migrantes con residencia legal, pero con problemas de integración social, incorporación al mercado laboral o vulnerabilidad social, la asistencia se extiende a la provisión "de una renta mensual en su país de origen que, aunque sea de cuantía inferior a la que le hubiese correspondido percibir como consecuencia de derechos adquiridos en el país de acogida, puede resultar interesante al extranjero retornado por el distinto nivel de vida entre los dos países" (Sánchez y Fernández, 2010, p. 139).

En el caso de migrantes en situación de irregularidad, "estos programas constituyen una alternativa a la expulsión, y permiten al extranjero elegir las condiciones de su retorno (lugar y momento), beneficiándose de una ayuda económica y de la asistencia en la preparación del retorno" (Sánchez y Fernández, 2010, p. 139). Por ello, en este último caso, se ha señalado que una de las ventajas de estos programas de retorno voluntario asistido tiene que ver con un uso más eficiente de los recursos públicos, en la medida de que facilita la repatriación de extranjeros porque poseen "un coste menor que el que conlleva la expulsión" (Sánchez y Fernández, 2010, p. 139).

Por ello, este último caso es el más interesante, toda vez que provoca que la distinción entre retorno voluntario y forzoso sea borrosa, "en la medida que las personas implicadas no tienen posibilidad legal de permanecer en el país de acogida" (Sánchez y Fernández, 2010, p. 139). Lo anterior es una razón que justifica analizar el PHRO a la luz de la práctica de expulsiones, lo que se hace en la sección final.

En torno a lo señalado, ¿cómo es la asistencia al retorno que provee el PHRO? El único beneficio que contempla consiste en lo siguiente: "disponiéndose de medios de transporte o pasajes de forma gratuita para su traslado -nacional e internacional- desde su lugar de residencia en Chile hasta el país de su nacionalidad" (Resolución Exenta №5744 de 2018, №3 parte Resolutiva). Asimismo, el PHRO no determina el tipo de beneficios según el estatus migratorio de sus 
beneficiarios, por el contrario, el PHRO contempla los mismos beneficios para todos los migrantes, sin distinguir su estatus migratorio, según se desprende de sus requisitos (Ministerio del Interior y Seguridad Pública y la Subsecretaría del Interior, 2018, №5 parte Resolutiva).

Por otra parte, la otra cuestión central que surge respecto del PHRO es si las razones esgrimidas por el gobierno para implementarlo son realmente razones humanitarias: esta es la denominación que la propia Resolución Exenta utiliza. En el derecho internacional de los derechos humanos, se entiende por humanitario: "Cualquier cosa beneficiosa para la humanidad en general o para un grupo particular de personas en una circunstancia particular: garantizar el respeto por la dignidad humana de los seres humanos" (Victor Condé, 2004, p. 144).

En este sentido debe entenderse la asistencia humanitaria que deben prestarse los Estados, como miembros de la comunidad internacional, la que generalmente se vincula con "proveer de suministros de socorro, alimentos y medicamentos a personas que están expuestas a un desastre público, natural o provocado por el hombre" (Victor Condé, 2004, p. 144).

La asistencia humanitaria tiene dos sentidos, como ayuda humanitaria o de emergencia y como asistencia para el desarrollo: "La primera, se otorga a los países en situaciones de emergencia, como un desastre natural, mientras que la segunda se refiere a un cambio planificado, incremental y sostenible a largo plazo" (Mónico y Smith Rotabi, 2014) ${ }^{10}$.

De allí que el PHRO no puede ser humanitario en el primer sentido antedicho, ya que en Chile no estamos frente a ninguna situación de emergencia o catástrofe que justifique la implementación de un plan humanitario. Tampoco el PHRO puede ser considerado humanitario en el segundo sentido, como asistencia para el desarrollo, ya que el gobierno chileno no se ha comprometido a largo plazo con el bienestar de los migrantes que se han acogido al plan, principalmente haitianos, una vez que se encuentren en su país de origen.

Esto es concordante con lo señalado por la OIM, en cuyo concepto, un programa de retorno voluntario asistido debe venir acompañado de medidas efectivas, tales como la asistencia para la reintegración a corto y mediano plazo ${ }^{11}$.

10 Cabe destacar, que no se debe confundir la asistencia humanitaria con la asistencia humanitaria a las víctimas de la guerra del Derecho Internacional Humanitario, que es el derecho internacional de la guerra, el jus in bellum, el que busca proteger a las víctimas de los conflictos armados, estableciendo límites a los medios y métodos de hacer la guerra, así como facilitando la asistencia humanitaria a dichas víctimas. Se contiene fundamentalmente en las cuatro Convenciones de Ginebra, enfocadas en los conflictos armados entre Estados y sus protocolos adicionales.

11 "El Marco propone una hoja de ruta para abordar el retorno voluntario y la reintegración de manera integral, una que responda a las necesidades de los retornados individuales, las necesidades de las comunidades a las que regresan y las prioridades de los gobiernos interesados, llamando a la adopción de medidas coordinadas, 
Por otra parte, el cambio de acento en la política migratoria chilena se expresa, como vimos, en las medidas administrativas arriba mencionadas, las que incluyen el PHRO, y en la urgencia e indicaciones dadas al proyecto de Ley sobre Migración y Extranjería ${ }^{12}$.

Tal cambio de acento se ha apreciado en otras legislaciones y se le ha denominado giro gerencial de las políticas de control migratorio, vale decir: "la organización de la selectividad, el reajuste eficiente del control migratorio, la cooperación entre agencias de acuerdo con objetivos sistémicos o la mejora del rendimiento del régimen de deportación" (Fernández y Brandariz, 2016, p. 7) ${ }^{13}$. Por ejemplo, llama la atención que el PHRO se haya aplicado de manera selectiva primeramente a la comunidad haitiana, a pesar de que la propia Resolución Exenta, señala como materia que "dispone Plan Humanitario de regreso ordenado al país de origen de ciudadanos extranjeros" (Ministerio del Interior y Seguridad Pública y la Subsecretaría del Interior, 2018).

La razón de ello se encuentra, aparentemente, en que dicho plan habría sido solicitado por la propia comunidad haitiana, como señala la Resolución Exenta que estableció el $\mathrm{PHRO}^{14}$. No obstante, la comunidad haitiana resulta ser la más vulnerable para la aplicación del plan, teniendo en cuenta las barreras lingüísticas que impiden determinar a cabalidad si la manifestación de la voluntad de acogerse a dicho plan se realizó de manera libre y voluntaria y en pleno conocimiento de "los derechos y obligaciones que le asisten como extranjero habitante de la República de Chile"15, fórmula que se repite en varias partes de la Resolución Exenta que estableció el PHRO ${ }^{16}$.

Por ello, el concepto mismo de voluntariedad que el PHRO presupone queda en tela de juicio, si se le mira desde el punto desde las directrices internacionales sobre el tema. Así, para la Organización Internacional para las Migraciones (2018):

Se supone que existe voluntariedad si se aplican dos condiciones: (a) libertad de elección, que se define como la ausencia de presión física o psicológica para inscribirse en un programa de Retorno Voluntario Asistido y Reintegración; y (b) una decisión informada, que requiere la disponibilidad de información oportuna, imparcial y confiable sobre

políticas y prácticas entre las partes interesadas responsables de la gestión y el desarrollo de la migración a nivel internacional, nacional y local" (OIM, 2018, p. 2).

12 Boletín №8.970-06 (04/06/de 2013).

13 También llamada migration managment o gobernabilidad migratoria. Para el desarrollo de este enfoque gerencial sobre la migración en Sudamérica. Véase Domenech (2018).

14 Resolución Exenta №5744 de 2018, letras a) y b) de su parte Considerativa.

15 Un informe del Departamento de Extranjería señala justamente las dificultades no solo lingüísticas de la población haitiana para insertarse en la sociedad chilena y conocer y exigir sus derechos. Véase DEM (2016). 
la cual basar la decisión. En algunos casos, profesionales calificados pueden necesitar una evaluación para determinar en qué medida una persona es capaz de tomar tal decisión libre e informada, y quien, si la persona carece de tal capacidad, podría tomar la decisión legalmente, en su nombre. (p. 6)

En este sentido, el PHRO no establece mecanismos para controlar públicamente que ambas condiciones de la voluntariedad que señala la OIM se cumplan. El PHRO no dispone de medidas efectivas que protejan o apoyen la decisión de acogerse al PHRO dada la situación de vulnerabilidad en que se encuentran quienes se acogen a él. Presumir la libertad de elección plena, es la marca distintiva del enfoque reduccionista del retorno de migrantes antedicho.

Por otra parte, se debe tener presente lo que señala la Convención sobre los trabajadores migratorios respecto de las personas que hayan solicitado o ya posean estatus de refugiado, caso que queda excluido de la aplicación de dicha Convención ${ }^{17}$. Por el contrario, el PHRO se aplica también al caso de extranjeros que hayan solicitado o ya posean estatus de refugiado ${ }^{18}$.

El aspecto antedicho del PHRO, no solo va en contra de las advertencias de la Agencia de la ONU para los refugiados (ACNUR) de que "carece de sentido trazar una línea estricta entre lo que son el desplazamiento voluntario y el desplazamiento forzado de personas" (Corte Interamericana de Derechos Humanos, 2003), dada la complejidad del fenómeno migratorio actual, lo que se expresa en la dificultad de "la determinación de una línea clara entre migrantes y refugiados" (Corte Interamericana de Derechos Humanos, 2003) ${ }^{19}$; sino que a su vez muestra "la erosión de derecho de asilo": la tendencia a colapsar el derecho individual subjetivo de asilo en la facultad discrecional del Estado de concederlo (Corte Interamericana de Derechos Humanos, 2003) 20 .

La evaluación del PHRO ha puesto el acento en los estándares internacionales respecto del propósito, forma, garantías y beneficios que deben contemplar los planes de retorno y su calificación como plan humanitario. Ahora bien, ¿qué resultados se obtienen si se compara el PHRO a la luz del sistema de expulsiones chileno? En lo sucesivo se ofrecerá una reconstrucción de dicho sistema y una evaluación del PHRO a partir de él.

17 Convención internacional sobre la protección de los derechos de todos los trabajadores migratorios y de sus familiares, Nueva York (18 de diciembre de 1990), artículo 3 letra d).

18 Resolución Exenta №5744 de 2018, letra g parte Resolutiva. Las condiciones para el retorno voluntario de refugiados poseen una regulación especial según el derecho internacional. Véase Derechos Humanos de Personas Migrantes. Manual Regional (2017, p. 111).

19 Intervención de la ACNUR.

20 Voto concurrente del juez AA. Cançado Trindade. 


\section{Formas expulsión de extranjeros en Chile}

En Chile un extranjero que enfrenta un proceso de expulsión por infracción administrativa a la ley migratoria tiene menos garantías a sus derechos que si enfrenta dicho proceso de expulsión producto de la comisión de un delito. Esto impacta de manera significativa la práctica jurídica de expulsión de extranjeros en Chile.

Esta situación se produce porque en nuestro sistema jurídico coexisten dos regímenes de expulsión de extranjeros: el penal y el administrativo, pero, como veremos, con una marcada tendencia hacia su convergencia. Si bien, es relevante distinguir ambos sistemas, que es lo que se hará a continuación, se deben presentar, al mismo tiempo, de manera sistemática como parte de una misma práctica jurídica, ya que ello permitirá apreciar la naturaleza jurídica del PHRO. En la siguiente tabla se resumen a grandes rasgos estos mecanismos:

\subsection{Régimen penal}

El primer régimen de expulsión se inserta en un proceso penal, el que está altamente reglado y donde existen garantías para el debido proceso. En él, la expulsión es concebida como una alternativa "que permite sustituir determinadas condenas impuestas a extranjeros" (Maldonado, 2015, p. 251) ${ }^{21}$, en los casos en que un extranjero sin residencia legal en Chile cometiera un delito en territorio nacional y fuera condenado "a una pena igual o inferior a cinco años de presidio o reclusión menor en su grado máximo" (Ley №18.216, 1983, art. 34). Aquí, "el juez, de oficio o a petición de parte, podrá sustituir el cumplimiento de dicha pena por la expulsión de aquél del territorio nacional” (Ley №18.216, 1983, art. 34). Dicha expulsión incluye la prohibición "de regresar al territorio nacional en un plazo de diez años" (Ley №18.216, 1983, art. 34).

Bajo este régimen, durante la audiencia donde se resuelve la sustitución de la pena privativa de libertad por la expulsión de territorio nacional "deberá ser citado el Ministerio del Interior y Seguridad Pública, a fin de ser oído" (Ley №18.216, 1983, art. 34) y si se ordena la expulsión "deberá oficiarse al Departamento de Extranjería del Ministerio mencionado para efectos de que lleve a cabo la implementación de esta pena y se ordenará la internación del condenado hasta la ejecución de la misma" (Ley №18.216, 1983, art. 34) ${ }^{22}$.

21 Esta forma de expulsión se encuentra contemplada en el artículo 34 de la Ley №18.216 de 1983, modificada por la Ley №20.603 de 2012.

22 Dicha posibilidad fue introducida tomando en cuenta la experiencia de la legislación española que contempla la expulsión como pena sustitutiva (Salinero, 2012, p. 489). Véase también Salinero (2011, p. 114 y ss). Lo mismo puede deducirse de la historia fidedigna de la Ley №18.216. Véase Historia de la Ley №20.603 (2012, p. 1007). 
Programas de Retorno Voluntario. El caso chileno

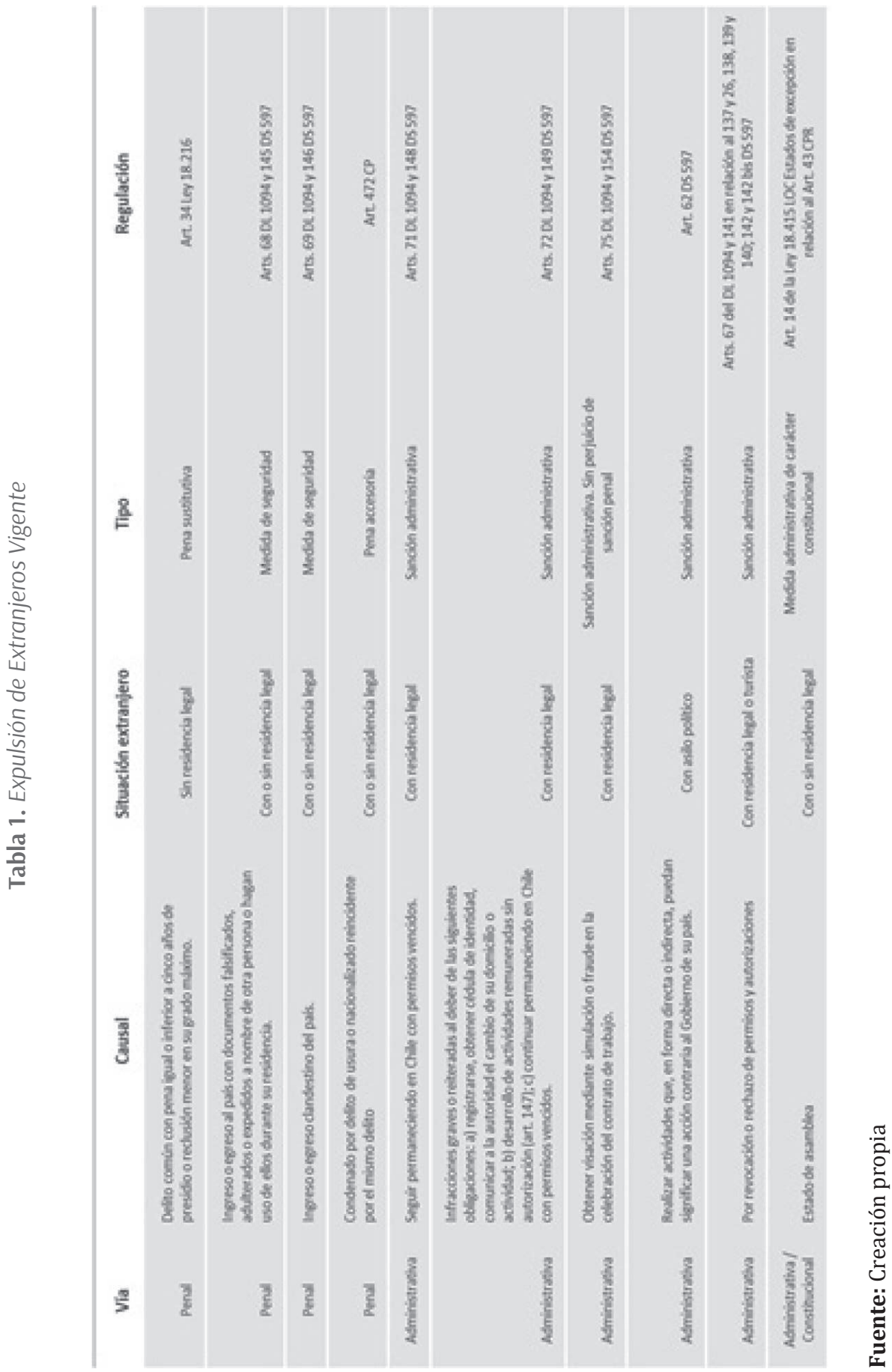


Lo común a todos estos casos es el efecto jurídico que producen, a saber: "en todos esos casos se puede afirmar concretamente que el condenado ha cumplido con la obligación impuesta en su condena, con total independencia de que para ello no haya satisfecho la pena determinada inicialmente en dicho instrumento" (Maldonado, 2015, p. 252).

Se ha dicho que la expulsión en este caso tiene un carácter ambiguo, debido a que ella podría potencialmente beneficiar al extranjero. Por ello, según el punto de vista "podrá ser una suspensión condicional de la pena o una retribución en su sentido clásico" (Salinero, 2011, p. 125) ${ }^{23}$.

Se adujo como una de las razones para contemplar esta pena sustitutiva que:

La normativa vigente en materia de extranjería [Decreto Ley №1094 y Decreto Supremo №597] contempla la posibilidad de expulsar a todo condenado que haya cumplido su pena y el proyecto pretende adelantar la expulsión al momento en que tal pena es impuesta. (Historia de la Ley №20.603, 2012, p. 1007)

Por ello, estamos más bien ante un caso de "excepción o renuncia a la pena aplicable a una determinada especie de personas. Sería una causa levantamiento de pena cuya finalidad es excluir del sistema jurídico a una categoría de personas" (Salinero, 2011, p. 123). Hacia el final volveremos a esta idea, que opera en base a una lógica del apartamiento.

Por otra parte, también integran el régimen penal los delitos especiales descritos en el Decreto Ley №1094 y el Decreto Supremo №597. A pesar de su naturaleza de legislación administrativa, dichos decretos "contempla una serie de disposiciones que [...] tienen naturaleza penal, pues, existe una descripción típica sancionada con una pena" (Salinero, 2011, p. 113).

Se trata de las sanciones a los extranjeros que ingresen o egresen del país mediante "documentos falsificados, adulterados o expedidos a nombre de otra persona o hagan uso de ellos durante su residencia" 24 o lo hagan "clandestinamente" (Ministerio del Interior, 1975, artículo 68 y 69, y Ministerio del Interior, 1984, artículo 145 y 146).

Las sanciones a los extranjeros, además de las penas señaladas, incluyen su expulsión una vez cumplida su pena y el impedimento o prohibición de ingreso ${ }^{25}$.

\footnotetext{
23 En el mismo sentido, Muñoz Ruiz (2014, p. 05:11).

24 Cabe destacar que este tipo penal no se aplica en casos de solicitantes de asilo político.

25 Decreto Ley №1094 de 1975, artículo 15, y Decreto Supremo №597 de 1984, artículo 26.
} 
Para ambos delitos, se deberá imponer la expulsión una vez cumplida la pena ${ }^{26}$. En la doctrina penal se ha discutido si la expulsión en estos casos se trata "de una pena, de una medida de seguridad, de un sustitutivo penal, de una condición suspensiva o de una medida administrativa" (Salinero, 2011, p. 119).

En cualquier caso, para estos delitos, el titular exclusivo de la acción penal pública la tiene el Ministerio del Interior o los Intendentes Regionales cuando se haya realizado delegación, mediante denuncia o requerimiento, "quienes tiene la facultad de desistirse de la denuncia o requerimiento en cualquier tiempo, dándose por extinguida la acción penal" (Ministerio del Interior, 1975, artículo 78, y Ministerio del Interior, 1984, artículo 158). Este desistimiento no evita la expulsión, a pesar de la extinción de la acción penal.

Finalmente, la expulsión también se contempla en el régimen penal en el caso de delito de usura ${ }^{27}$. Al igual que en el caso de los delitos especiales, aquí también se configura la prohibición de ingreso, lo que impide el regreso a Chile del migrante ${ }^{28}$.

\subsection{Régimen administrativo}

El segundo régimen de expulsión, por el contrario, es discrecional. En principio, es una medida de autoridad administrativa facultada para disponerla. Aquí la expulsión se adopta como consecuencia de alguna infracción a lo señalado en los referidos Decreto Ley №1094 y Decreto Supremo №597.

Las causales de este tipo de expulsión son las siguientes: seguir permaneciendo en Chile con permisos vencidos ${ }^{29}$; por infracciones graves o reiteradas al deber de las siguientes obligaciones: a) registrarse, obtener cédula de identidad, comunicar a la autoridad el cambio de su domicilio o actividad, b) desarrollo de actividades remuneradas sin autorización, c) continuar permaneciendo en Chile con permisos vencidos ${ }^{30}$; obtener visación mediante simulación o fraude en la celebración del contrato de trabajo ${ }^{31}$; en el caso de asilados políticos, realizar ac-

Por ello, aquí el legislador "privilegia un criterio de prevención general, al exigirse el cumplimiento de la pena impuesta para la infracción respectiva, debiendo luego, ejecutarse la expulsión que es resorte privativo de la administración" (Salinero, 2011, p. 114).

27 Si se condena "por usura un extranjero, será expulsado del país; y condenado como reincidente en delito de usura un nacionalizado, se le cancelará su nacionalización y se le expulsará del país". Estableciéndose que "En ambos casos la expulsión se hará después de cumplida la pena” (Código Penal, artículo 472, inciso segundo y tercero).

La supervivencia del sistema penal de expulsión de extranjeros se enmarca dentro de la tesis de la crimigración, esto es, "la creciente interrelación entre control migratorio y sistema penal" (Brandariz, Dufraix y Quinteros, 2018, p. 742), que en este sentido no se opone, sino que complementa al giro gerencial que ha adoptado la política migratoria chilena desde 2018. 
tividades que, en forma directa o indirecta, puedan significar una acción contraria al Gobierno de su país ${ }^{32}$; por revocación o rechazo de permisos y autorizaciones ${ }^{33}$.

Por otra parte, la expulsión de extranjeros también puede decretarse como una medida administrativa de carácter constitucional, en el estado de excepción constitucional de asamblea ${ }^{34}$.

Los puntos más cuestionables de estas medidas de expulsión administrativa han sido tres. El primero, más que la variedad de sus causales ha sido la forma en cómo se aplican dichas medidas, ya que, tal como señalan dichos cuerpos legales ${ }^{35}$, corresponden al ejercicio de una potestad discrecional del Ministerio del Interior, la que queda constreñida explícitamente en lo sustancial, "a la conveniencia o utilidad que reporte al país la concesión de estos permisos, y a la reciprocidad internacional" y en lo formal, a un informe previo de la Dirección General de Investigaciones (Meza-Lopehandía, 2014, pp. 11-12).

Sobre este aspecto se pronunció el Tribunal Constitucional chileno ${ }^{36}$, señalando la necesidad de reemplazar la máxima discrecionalidad administrativa del Ministerio del Interior por un enfoque de derechos humanos ${ }^{37}$. Asimismo, el Tribunal señala algo muy relevante sobre la norma del artículo 13: que ella sería parte de la legislación de la dictadura, adoptada sin criterios constitucionales de derechos fundamentales, "preconstitucionales", ni de derecho internacional de derechos humanos, "pre-convencionales", razón por la cual "deben ajustarse a la condición de derechos que tiene un extranjero que ya ingresó legalmente al país y que sorteó los requisitos iniciales habilitantes contemplados por el legislador, según lo dispone la Constitución" (Requerimiento de inaplicabilidad por inconstitucionalidad del ciudadano haitiano Daniel Alerte (2013), considerando trigésimo séptimo) ${ }^{38}$.

32 Decreto Supremo №597 de 1984, artículo 62.

33 Decreto Ley №1094 de 1975, artículo 67 en relación al 63, 63, 64, 65 y 66, y Decreto Supremo №597 de 1984, artículo 141 en relación, al 137 y 26, 138, 139 y 140; 142 y 142 bis.

34 Ley №18.415 de 1985, artículo 14 en relación Constitución Política, artículo 43.

35 Decreto Ley №1094 de 1975, artículo 13, y Decreto Supremo №597 de 1984, artículo 13.

36 Requerimiento de inaplicabilidad por inconstitucionalidad del ciudadano haitiano Daniel Alerte (2013), considerando trigésimo cuarto. En un caso semejante, Requerimiento de inaplicabilidad por inconstitucionalidad de la ciudadana haitiana Sonia Fortilus (2013), cuya sentencia es muy próxima a la mencionada, el Tribunal Constitucional rechazó la declaración de inconstitucionalidad de dicho artículo.

37 El Ejecutivo ha venido realizando esfuerzos en este sentido. Primero, con el envío de proyectos de ley que buscan sustituir el Decreto Ley №1094, Boletín №8.970-06 (04/06/2013), el que actualmente se encuentra en segundo trámite constitucional, y Boletín №11.395-06 (23/08/2017). Asimismo, con la creación del Consejo de Política Migratoria, mediante el Decreto №1393 de 2014, y el Consejo Técnico de Política Migratoria, mediante Decreto №108 de 2015. En todos estos casos se buscaba adoptar una perspectiva de derechos para la regulación de la migración. Jarufe (2019).

38 Se ha señalado que el Decreto Ley №1094 más que una norma preconstitucional y preconvencional "es resultado de una legislación anómala, propia de la ruptura del orden democrático, una normativa marginal 
En segundo lugar, se ha criticado que la expulsión de régimen administrativo sea solo una medida de autoridad administrativa facultada para disponerla de manera discrecional. Más bien, ella posee una naturaleza sancionatoria, la que la hace equiparable a la sanción que contempla el régimen penal ${ }^{39}$. De esta manera, si ambos regímenes, el penal y el administrativo, establecen sanciones, entonces los estándares del debido proceso, tanto sustantivos como procesales, deberían aplicarse en ambos, aunque de manera atenuada en el caso del régimen administrativo, como han señalado la jurisprudencia y buena parte de la doctrina nacional ${ }^{40}$.

Sobre esto, se ha enfatizado que el régimen administrativo de expulsiones no satisface las garantías del debido proceso, ya que carece de "un proceso administrativo establecido y objetivo" (Díaz, 2016, p. 206) ${ }^{41}$, y la decisión de la autoridad administrativa es ciega a factores relevantes como "arraigo familiar, antecedentes judiciales, de vulnerabilidad o peligro de retorno del migrante a su país de origen" (Bassa y Torres, 2015, p. 118). Asimismo, que afecta el acceso a la justicia, considerando los brevísimos plazos de impugnación judicial de los decretos de expulsión ${ }^{42}$.

Esto es especialmente relevante, ya que en la práctica lo que ha ocurrido es que la autoridad ha tenido a aplicar el régimen administrativo de forma sustitutiva al régimen penal. Ello, porque, como vimos, el titular exclusivo de la acción penal pública la tiene el Ministerio del Interior o los Intendentes Regionales, señalándose que dichas autoridades podrán desistirse de la denuncia o querella extinguiendo la acción penal.

que opera bajo la ausencia de límites, que, dicho sea de paso, se conciben en el Estado democrático a partir de los derechos fundamentales" (Galdámez, 2013, pp. 779-780).

39 En este mismo sentido, Carrasco y Parra (2019).

40 Por ejemplo, Compañía Minera Zaldívar Limitada con Secretaria Regional Ministerial de Salud (2014), considerando decimotercero. Véase Cordero Quinzacara (2012, 2013 y 2014); Enteiche (2014). En general, se considera en Chile que cualquier procedimiento administrativo sancionador debe respetar al menos las siguientes garantías: "el oportuno conocimiento de la acción", "la existencia de un debido emplazamiento", "el establecimiento de un plazo de investigación", "la existencia de una conducta sustantivamente descrita" (tipicidad), "la asistencia de un abogado defensor", "la bilateralidad de la audiencia”, "la aportación de pruebas pertinentes y el derecho a impugnar lo resuelto mediante recursos ordinarios o especiales" (Carrasco y Parra, 2019, p. 337-349). No obstante, hay también buenas razones para comprender la potestad sancionadora administrativa de forma tal de diferenciarla de las sanciones penales, justamente en base a las diferentes garantías que se aplicarían en uno y otro caso. Véase Letelier (2017).

41 Así, "en cuanto a instancias de reclamación, si bien el decreto ley las establece tanto para el rechazo o revocación de la solicitud, como para la orden de expulsión, están lejos de cumplir con los estándares internacionales que prevén la posibilidad de defenderse en un debido proceso [...] pues resultan prácticamente imposibles de ejercer, en consideración de los plazos breves que se disponen y el contexto coercitivo que las rodean, máxime si una persona jamás ha conocido, litigado, alegado derechos y, previsiblemente incluso, no conozca el idioma que lo permita" (Díaz, 2016, p. 206)

42 Afecta el acceso a la justicia, ya que solo es posible presentar un recurso de reclamación contra un decreto de expulsión, dentro del plazo de 24 horas y ante la Corte Suprema, Decreto Ley №1094 de 1975, artículo 89, y Decreto Supremo №597 de 1984, artículo 174. Pero, la razón fundamental consiste en que "durante la resolución del recurso, el inmigrante puede ser privado de libertad, medida que no es decretada por un tribunal de justicia, sino por la autoridad administrativa" (Bassa \& Torres, 2015, p. 118). 
Lo que ha ocurrido en la práctica es preocupante. Por ejemplo, en el caso del delito de ingreso clandestino, "el Intendente Regional realiza la respectiva denuncia para iniciar un proceso penal. Inmediatamente después, la administración se desiste de la acción. Esto apareja dos consecuencias, una es la extinción de la responsabilidad penal del inmigrante, y la otra es que habilita a la administración a dictar el decreto de expulsión" (Cruz, 2018, p. 11).

Las posibles razones para adoptar esta estrategia por parte del órgano administrativo son: la menor complejidad argumentativa y probatoria del proceso sancionatorio de expulsión respecto del proceso penal, los menores costos de transacción y la mayor previsibilidad de expulsar a extranjeros por vía administrativa. Estos elementos, como vimos, son típicos del giro gerencial en la política de migración.

La Corte Suprema, conociendo de recursos de amparo con motivo de expulsiones, a propósito del delito especial de ingreso clandestino, ha desarrollado tres criterios jurisprudenciales a fin de atajar el problema de la sustitución de los regímenes: "El primer criterio es el llamado 'germen de arraigo'", donde la Corte ha valorado positivamente diversas situaciones que benefician al migrante: trabajo, matrimonio con un nacional, hijos nacidos en Chile, entre otras ${ }^{43}$. El segundo criterio "es la exigencia de una investigación penal previa al decreto de expulsión" (Cruz, 2018, p. 6), a fin de evitar la estrategia de sustituir el régimen penal por el administrativo en el caso de expulsiones ${ }^{44}$. El tercer criterio, consiste en no tener en cuenta los criterios anteriores, en la medida que el extranjero cuente con antecedentes penales ${ }^{45}$.

En tercer lugar, dicho régimen de expulsión administrativa es, desde el punto de vista de sus normas, disperso, ya que, junto a los principales cuerpos normativos mencionados, su regulación se completa mediante "otras normas específicas y una

43 Por ejemplo, sentencias de los casos Marlenay Moreno de la Cruz con Intendencia de Arica y Parinacota (2017); Leonarda Pujols Rosario con Intendencia de la Región de Arica y Parinacota (2017); y Ayda Riascos Asprilla con Intendencia regional de Los Lagos (2017).

44 Por ejemplo, sentencias de los casos Marisol Marte Rodríguez con Intendencia Regional de Arica y Parinacota (2017); y Juana Geraldo Domínguez contra Intendencia Regional de Arica y Parinacota (2017)

45 Por ejemplo, sentencia en los Leidy Gálvez Ospina con Ministerio del Interior y Seguridad Pública (2019). Esto ha sido relevante también en casos mediáticos recientes, como el de Reilly con Ministerio del Interior y otro (2017); y el de Recurso de Amparo presentado por el INDH ante la Corte de Apelaciones de Antofagasta en favor de 6 ciudadanos colombianos, que fueron citados por la PDI mediante engaños, el que fue rechazado, atendiendo entre otros argumentos al desarrollado en el considerando octavo: "A mayor abundamiento, no es procedente utilizar el argumento de la protección y arraigo familiar, para obviar la hipótesis legislativa, sostener dicha tesis significaría desvirtuar los fines de la norma, los cuales se identifican con la seguridad nacional" (Instituto Nacional de Derechos Humanos con Departamento de Extranjería y Migración, 2019). Dicha sentencia fue confirmada por la Corte Suprema en sentencia causa Rivera Constanza y otros (INDH) con Departamento de Extranjería y Migración del Ministerio del Interior y Seguridad Pública y otro (2019). 
variada regulación administrativa a través de oficios, instructivos y circulares" (Bassa y Torres, 2015, p. 106).

Pero esta dispersión no debe llevar a conceptuar de manera separada los diversos regímenes de expulsión de extranjeros en Chile. Por ello, para comprender a cabalidad la verdadera naturaleza jurídica del PHRO, se debe describir la práctica jurídica como un todo, la que, si bien encuentra su principal fundamento en el Decreto Ley №1094 y el Decreto Supremo №597, se ha ido desarrollando en la aplicación de dichas normas por parte de la administración y los tribunales superiores de justicia, tratando de conformarlas a un paradigma de derechos.

Asimismo, dicha dispersión, ha permitido que, en la medida que cambien las circunstancias políticas, se alteren los criterios de aplicación de la legislación migratoria. Esto muestra la urgencia y necesidad de contar con una nueva regulación migratoria, acorde con un Estado democrático y con una perspectiva de Derechos Humanos.

En este sentido, la dispersión de las fuentes no solo contribuye a acrecentar la falta de claridad sobre los sistemas de expulsión de extranjeros en Chile, sino que impide apreciar la verdadera naturaleza jurídica del PHRO, a saber, las consecuencias de la aplicación del PHRO para los extranjeros que se acogen a él: la prohibición de regreso. En lo sucesivo nos abocaremos a este asunto.

\section{El PHRO a la luz de los regímenes de expulsión}

¿Cuál sería la naturaleza jurídica de la expulsión en los regímenes penal y administrativos antedichos? Varios actores que participan de la práctica de expulsiones tienen opiniones diversas.

Para la Defensoría Penal Pública, la expulsión posee un carácter mixto, ya que es "al mismo tiempo una sanción administrativa y penal, incluyendo su carácter de pena sustitutiva" (Departamento de Estudios y Proyectos. Defensoría Penal Pública, 2014, p. 13). Asimismo, destaca el carácter ambiguo del régimen administrativo de expulsiones, ya que considera que "La expulsión administrativa es a la vez una sanción y una facultad administrativa. Es una sanción porque puede decretarse en casos de extranjeros denominados irregulares" (Departamento de Estudios y Proyectos. Defensoría Penal Pública, 2014, p. 13).

El problema clave parece ser el carácter ambivalente del régimen administrativo de expulsiones, en el entendido de que ordenar la expulsión de un extranjero sería el ejercicio de una potestad entregada por la Ley a un órgano administrativo, pero, al mismo tiempo, sería una sanción de naturaleza administrativa que dicho órgano puede imponer a un extranjero. 
Si se tratare de una sanción, y, como tal, resultado del ejercicio del ius puniendi estatal, "las garantías del orden penal se aplican con matices al Derecho Administrativo sancionador" (Enteiche, 2014, p. 294) ${ }^{46}$, especialmente las de tipicidad y legalidad, tal y como ha señalado mayoritariamente la doctrina y jurisprudencia nacional, y que, como vimos, ha sido una de las críticas que se han dirigido a este régimen, especialmente al procedimiento y sus brevísimos plazos establecidos en el artículo 89 del Decreto Ley №1094.

Por el contrario, si se tratase de una facultad, a pesar de la necesidad de adoptar un enfoque de derechos, como sostuvo el Tribunal Constitucional, lo que obligaría a cautelar el estándar del debido proceso, sí cabría un grado de discrecionalidad a la administración, aunque no máximo, dadas las potestades entregadas a ella por la Ley y Reglamento de Extranjería vigentes para decidir respecto de la expulsión de extranjeros.

Por ello, partiendo del supuesto carácter facultativo y discrecional del régimen administrativo de expulsiones, es evidente que dicho régimen establece un estándar de argumentación y control judicial menor respecto del régimen penal. Este ha sido el caso, como se señaló, del delito de ingreso clandestino, donde los órganos de administrativos han preferido sustituir el régimen penal de expulsiones por el régimen administrativo, hasta el límite que impuso la Corte Suprema mediante sus criterios jurisprudenciales.

La relevancia de este punto queda de manifiesto, si se atiende a los límites que el derecho internacional de los Derechos Humanos establece a las expulsiones de extranjeros en régimen administrativo:

Se debe considerar que la medida de expulsión no es una pena, sino el fruto de una potestad de policía de seguridad; por tanto, si fuese una medida inmotivada o carente de fundamento, aun tratándose de medidas aplicadas en virtud de alguna disposición de la Ley de Extranjería, se generaría responsabilidad del Estado, que puede ser ventilada ante un órgano jurisdictor de derecho internacional por el Estado a que pertenece el extranjero. (Díaz, 2016, p. 197)

46 Además de la referida sentencia de la Corte Suprema en el caso Compañía Minera Zaldívar Limitada con Secretaria Regional Ministerial de Salud (2014), se encuentran las sentencias del Tribunal Constitucional en los casos Requerimiento de inaplicabilidad por inconstitucionalidad de compañía eléctrica san isidro S.A. y otras (2006), considerando décimo, Control de constitucionalidad del proyecto de ley que modifica la Ley №4.601, Ley de Caza (2006), considerandos noveno y décimo, y Requerimiento de inaplicabilidad por inconstitucionalidad de don Hernán Pfeifer Frenz y otros (2010), considerando sexto; y en diversos dictámenes de la Contraloría General de la República: Dictamen 063697N11 (7 de octubre de 2011) y Dictamen 013790N13 (28 de febrero de 2013). Para el caso específico de las expulsiones mediante un procedimiento administrativo, deberían aplicarse todas las garantías del debido proceso, tanto las sustantivas como las procesales. Véase Carrasco y Parra (2019). 
En este sentido, como vimos, los estándares internacionales en materia de expulsiones reconocen la potestad de los Estados de restringir la libertad de circulación, de escoger residencia y de salir de cualquier país que tienen los extranjeros, aunque las someten a ciertos límites ${ }^{47}$. Esto, en el entendido de que se trata de regímenes administrativos que son una manifestación del ejercicio de una potestad pública facultativa, aunque no ilimitada, de la autoridad de los Estados y, por ende, propia del derecho interno.

Por ello, aquí hay una doble tensión entre la protección internacional y el derecho interno. Por una parte, el régimen chileno es mixto: penal y administrativo, a diferencia de lo que indican los estándares internacionales, que tienden a no criminalizar la migración ilegal. Por otra, dentro de nuestra cultura jurídica hay razones para considerar al régimen administrativo de expulsiones como una manifestación del ius puniendi estatal y, por ende, sujeto también a las garantías atenuadas del debido proceso (al menos, tipicidad y legalidad). En este último punto, dado los pobres estándares en materia de debido proceso que contempla el Decreto Ley №1094, el Estado chileno sí estaría incumpliendo con obligaciones internacionales en materia de derechos. Esta es quizás la razón más poderosa para que Chile modernice su legislación migratoria.

No obstante, no hay unanimidad en nuestra cultura jurídica respecto a considerar la expulsión de extranjeros como parte del ejercicio del derecho administrativo sancionador. Ello se apoya, no solo en lo señalado en el mencionado artículo 13 del Decreto Ley №1094 y del Decreto Supremo №597, que alude a que las "atribuciones" del Ministerio del Interior "serán ejercidas discrecionalmente", sino que también al uso invariable del legislador de la expresión "pueda disponerse su abandono obligado del país o su expulsión", que indica su carácter facultativo. En estos casos, entonces, estaríamos frente una medida de la autoridad facultada para disponerla.

Esta interpretación es la que, por ejemplo, ha seguido la Contraloría respecto del Decreto Ley №1094 y Decreto Supremo №597, ya que ha sostenido que "la expulsión constituye una medida de la autoridad facultada para disponerla y no una sanción administrativa" (Contraloría General de la República, 2016, 13 de mayo de). Dicha interpretación claramente tensiona la interpretación que, como vimos, ha realizado el Tribunal Constitucional.

47 En este sentido, con respecto al artículo 12 del Pacto internacional de derechos civiles y políticos, Nueva York (16 de marzo de 1966), se ha dicho: “La cuestión de si un extranjero se encuentra 'legalmente' dentro del territorio de un Estado es una cuestión regida por el derecho interno, que puede someter a restricciones la entrada de un extranjero al territorio de un Estado, siempre que se adecuen a las obligaciones internacionales de ese Estado" (Observación General №27 del Comité de Derechos Humanos de Naciones Unidas [2 de noviembre de 1999], parágrafo 4). 
Por otra parte, dicha ambigüedad sobre la naturaleza de la expulsión en el régimen administrativo también contribuye a obscurecer sus similitudes con las del régimen penal, en lo que respecta a los efectos de tales expulsiones. Este punto es clave para determinar la naturaleza jurídica del PHRO.

En principio, los regímenes penales y administrativos contemplan la prohibición de regreso al territorio nacional como consecuencia de la expulsión. La cuantía temporal de dicha prohibición posee una salvedad: como vimos, en el caso del régimen pernal en el caso de la expulsión como pena sustitutiva, dicha prohibición de regresar al territorio nacional tiene un plazo de diez años ${ }^{48}$. El plazo antedicho, es semejante al que dispone el PHRO, que contempla una prohibición de regreso en un plazo de nueve años desde su salida del territorio nacional como beneficiarios del $\mathrm{PHRO}^{49}$. ¿Por qué un plan de retorno con un supuesto carácter humanitario tiene una prohibición de regreso tan estricta como la del régimen penal de expulsiones? La razonabilidad, constitucionalidad y convencionalidad de un plazo tan extenso para la prohibición de regreso, ha sido compartida por la Corte Suprema en un caso reciente ${ }^{50}$.

Respecto de las demás hipótesis del régimen penal y del régimen administrativo, dicho plazo se considera indefinido. Así lo ha establecido la Contraloría ${ }^{51}$. Ello quiere decir que la prohibición de regresar al país es indefinida, aunque, como señala el Decreto Ley N¹094: "podrán ser revocadas o suspendidas temporalmente en cualquier momento" 52 .

En la siguiente tabla se muestra una comparación del PHRO y de los regímenes de expulsión según sus efectos:

48 Ley №18.216 de 1983, artículo 34. Se considera a esta medida como una "renuncia del Estado al ius puniendi" Salinero (2011) p. 123, teniendo en cuenta que dicha expulsión se da en el caso de extranjeros sin residencia legal en Chile. Esto se ve refrendado por lo que señala la parte final del mismo artículo 34 de la Ley №18.216 de 1983: en el caso que el condenado regresare al territorio nacional dentro del plazo de la prohibición, en cuyo caso "se revocará la pena de expulsión, debiendo cumplirse el saldo de la pena privativa de libertad originalmente impuesta”. Esto debe interpretarse como una excepción a dicha renuncia.

49 (Resolución Exenta №5744 de 2018, punto 5 letra f).

50 La Corte de Apelaciones de Santiago, en la causa Haitianos con Ubilla (2019), conociendo de un recurso de protección en favor de 160 ciudadanos haitianos que se acogieron al PHRO, discutió la razonabilidad de la prohibición de regreso que contempla dicho plan. En su considerando octavo señala que "la recurrida ha explicitado todas y cada una de las razones que motivaron la dictación de la Resolución Exenta №5.744, de 2018", entre las que se encuentran que obedece a hechos de notoriedad y escrutinio público, a la legislación nacional, al contexto internacional y "la coherencia que la misma tendría con Convenios Internacionales que se encuentran vigentes", por lo a juicio de la Corte "no se visualiza ningún atisbo de reproche en la prohibición incorporada a la misma".

51 Dictamen №025128N14 (9 de abril de 2014).

52 Decreto Ley $\mathrm{N}^{\circ} 1094$ de 1975, artículo 84. 
Tabla 2. Tabla comparativa de mecanismos de expulsión de extranjeros.

\begin{tabular}{|c|c|c|c|c|c|}
\hline \multirow{4}{*}{ Régimen } & Causal & Pena & $\begin{array}{c}\text { Modalidad } \\
\text { Expulsión }\end{array}$ & Efectos & Duración \\
\hline \multirow{7}{*}{ Penal } & Delito común & $\begin{array}{c}\text { Pena } \\
\text { correspondiente }\end{array}$ & Pena sustitutiva & $\begin{array}{c}\text { Prohibición } \\
\text { de regreso }\end{array}$ & 10 años \\
\cline { 2 - 7 } & Delito de usura & $\begin{array}{c}\text { Pena } \\
\text { correspondiente }\end{array}$ & Pena accesoria? & $\begin{array}{c}\text { Prohibición } \\
\text { de regreso? }\end{array}$ & Indefinida? \\
\cline { 2 - 7 } & $\begin{array}{c}\text { Delitos especiales } \\
\text { DL 1094 }\end{array}$ & $\begin{array}{c}\text { Pena } \\
\text { correspondiente }\end{array}$ & $\begin{array}{c}\text { Medida de } \\
\text { seguridad? }\end{array}$ & $\begin{array}{c}\text { Prohibición } \\
\text { de regreso }\end{array}$ & Indefinida \\
\hline \multirow{2}{*}{ Administrativo } & $\begin{array}{c}\text { Infracción grave } \\
\text { DL 1094 }\end{array}$ & No hay & $\begin{array}{c}\text { Sanción } \\
\text { administrativa }\end{array}$ & $\begin{array}{c}\text { Prohibición } \\
\text { de regreso }\end{array}$ & Indefinida \\
\cline { 2 - 7 } & Voluntaria(PHRO) & No hay & $\begin{array}{c}\text { Decisión adm. } \\
\text { facultativa }\end{array}$ & $\begin{array}{c}\text { Prohibición } \\
\text { de regreso }\end{array}$ & 9 años \\
\hline
\end{tabular}

Fuente: Creación propia.

Una duración tan extensa de la prohibición de regreso en el caso del PHRO contrasta con la experiencia internacional en la implementación de planes de retorno voluntario, donde dicha prohibición no es ni punitiva ni indefinida. Por ejemplo, en el caso español, dicho plazo se establece en tres años y busca más bien salvaguardar una serie de prestaciones sociales que se pagan por anticipado al extranjero que retorna voluntariamente a su país de origen. Asimismo, "una vez agotado el plazo durante el cual se comprometió el no-regreso, los retornados a su país que deseen reemprender su vida laboral en España serán tratados de forma privilegiada" (Sánchez y Fernández, 2010, p. 154), en lo que respecta la obtención de sus permisos de residencia y trabajo.

\section{Conclusiones}

Conceptualmente, un plan humanitario en materia migratoria consistiría en facilitar el ingreso al país de extranjeros que se encuentren en una situación de precariedad económica y social en su país de origen, o bien implementar un plan de retorno que contemple reintegración, acogida y desarrollo de proyectos productivos, en el país de origen para los extranjeros que deseen regresar a él ${ }^{53}$. De las razones que se expresan en la implementación del PHRO, se desprende más bien un enfoque reduccionista y economista de la decisión de retorno, sustentado en la voluntariedad de la decisión de acogerse al plan.

53 Un buen ejemplo, es el plan establecido por la Unión Europea, que en 2008 creó el Fondo Europeo para el Retorno, establecido mediante Decisión №575/2007/CE del Parlamento Europeo y del Consejo. 
El PHRO no sería un plan humanitario, sino solo un mero plan de retorno voluntario con una pobre asistencia, el que, además, carece de las medidas para la reintegración a corto y mediano que promueve la OIM, cuya implementación sí daría el carácter de humanitario al PHRO. Más bien, el PHRO facilita o incentiva el regreso a la misma precariedad económica y social en el país de origen del extranjero y que, con toda probabilidad, fue la que en primer lugar le impulsó a migrar.

Por otra parte, a la luz de los estándares internacionales, el PHRO queda severamente cuestionado como plan de retorno o regreso, ya que se aplica también al caso de extranjeros que hayan solicitado o ya posean estatus de refugiado ${ }^{54}$. Estos cuestionamientos se ven acrecentados, considerando que la implementación del plan se realizó no por una ley en sentido estricto, sino mediante una resolución exenta, lo que implica en la legislación chilena la omisión del control de legalidad que ejerce la Contralaría General de la República sobre los actos de la administración: un control de tal órgano habría probablemente prevenido que el PHRO incluyera como potenciales beneficiarios a extranjeros que hayan solicitado o ya se encuentren en situación de asilo.

De esta manera, no son infundados los temores de la sociedad civil sobre el PHRO, ya que, al haberse aplicado primeramente a la comunidad haitiana, incluso en casos donde se ha solicitado formalmente asilo o ya se goza del estatus de refugiado, se refuerza la idea de que dicho plan constituye una deportación velada ${ }^{55}$.

Las consideraciones abordadas en las secciones anteriores ayudan a perfilar el argumento central de este trabajo, a saber, que el PHRO es, en realidad, una forma encubierta de deportación que, aunque voluntaria, es masiva y selectiva. Sus efectos son semejantes al de los regímenes de expulsión contemplados en la legislación chilena.

Frente al panorama esbozado sobre el PHRO y su relación con los regímenes de expulsión, hay dos preguntas muy relevantes que surgen, pero cuyo desarrollo rebasa los límites de este trabajo, por lo que solo ofreceré un ensayo de respuesta.

La primera, ¿cuál es la justificación de que la prohibición de regreso sea tan extensa en el caso del PHRO? Como se señaló, ello obedecería a una lógica del apartamiento, una que busca apartar del trato social a ciertas categorías de personas: extranjeros vulnerables que decidieron emigrar a Chile. Esto, en vez de socorrerlos e integrarlos en la sociedad. Por ello tiene sentido reconstruir y hablar del sistema de expulsiones como un todo, en su dimensión penal y administra-

54 Resolución Exenta №5744 de 2018, letra g parte Resolutiva. Las condiciones para el retorno voluntario de refugiados poseen una regulación especial según el derecho internacional. Véase Derechos Humanos de Personas Migrantes. Manual Regional (2017, p. 111).

55 Por ejemplo, esta ha sido la opinión de los principales dirigentes de migrantes. Véase Loyola y Urbina (2018) y Cancino Ávila (2018). 
tiva, ya que "ambos sistemas, el derecho penal y el derecho migratorio, son, en su núcleo, sistemas de inclusión y exclusión. Están diseñados de manera similar para determinar cómo se incluye a los individuos como miembros de la sociedad y cómo se excluyen" (Stumpf, 2006, p. 380).

Esta lógica es la que subyace finalmente a cualquier sistema de expulsión de extranjeros. Dicha lógica sería contraria a la hospitalidad que, en el Estado moderno, no consiste en un deber moral, como sí lo es para la tradición judeocristiana, sino que un derecho: "Significa hospitalidad el derecho de un extranjero a no recibir un trato hostil por el mero hecho de ser llegado al territorio de otro"(Kant, 1998, p. 27).Sostiene aquí la idea de que a todos los seres humanos nos asiste "el derecho a presentarse en una sociedad" (Kant, 1998, p. 27), es decir, a no ser privados del trato $^{56}$. Por ello, se ha recalcado elocuentemente: "que 'pensar la inmigración significa pensar el Estado' y que es 'el Estado el que se piensa a sí mismo pensando la inmigración'” (Sayad, 1996, p. 8).

La segunda, ¿es plausible la comparación por sus efectos de los regímenes de expulsión con el PHRO? Esto, porque a pesar de sus similitudes, a primera vista, una pena, una sanción administrativa y un beneficio solicitado voluntariamente por un interesado, parecen poseer una naturaleza jurídica completamente distinta.

Sobre esto, cabe señalar que la semejanza o diferencia de los regímenes penal y administrativo, en comparación con el PHRO, puede realizarse atendiendo a diversos elementos.

Una forma de hacerlo es apelando a la naturaleza administrativa o penal de las normas que los regulan, donde existen marcadas diferencias entre el PHRO y los regímenes penal y administrativo (órganos, procedimientos, estándares de valoración y fines distintos). Otra forma es apelando a su aplicación coactiva o voluntaria, donde el PHRO también sería claramente distinto de los regímenes penal y administrativo. Finalmente, apelando a los efectos que el PHRO y dichos regímenes poseen: en todos ellos los efectos son semejantes, ya que suponen la prohibición de regreso por un periodo extenso o indefinido de tiempo.

No hay razones para preferir un elemento por sobre otro, a la hora de comparar los regímenes de expulsiones con el PHRO, sobre todo si se busca describir la práctica de expulsiones de forma conjunta, como he tratado de hacer aquí.

No obstante, comparar o determinar la naturaleza jurídica de las normas por sus efectos es problemático. Lo es, porque atenta contra uno de los dogmas

56 Por ello, de estas ideas que Kant presenta en dicha obra, se puede llegar a la conclusión de que "Cuanto más se exprime el contenido de derechos humanos existente en la Ley Fundamental tanto más se asimila el estatuto jurídico de los no-ciudadanos que viven en la República Federal con el de los ciudadanos" (Habermas, 1997, pp. 81-82). 
de la teoría del derecho. En un famoso pasaje, Kelsen (1982) señala: "No es casi posible determinar el concepto de una pena (sanción penal) según su finalidad. Puesto que la finalidad de la sanción penal no proviene -o no proviene en forma inmediata- del contenido del orden jurídico" (p. 124).

Esta idea, de que no es posible develar la naturaleza jurídica de las normas a partir de los efectos que producen, está muy bien asentada en nuestra cultura jurídica. La ciencia penal posee la misma convicción, expresada en la idea de que la finalidad de la norma penal obedece a una cuestión de política criminal. En otras palabras, la verdadera naturaleza de las normas estaría en su estructura, no en sus fines. No obstante, la consecución de los mismos efectos jurídicos con normas o estatutos jurídicos distintos es parte de la práctica jurídica ordinaria.

De allí que, considerando que comparar las normas por los efectos que producen no es solo un problema teórico, sino también uno práctico, es posible concebir la práctica jurídica de las expulsiones de extranjeros como integrada por tres tipos de procedimientos: uno penal, uno sancionatorio administrativo y otro voluntario, los que cumplen el mismo objetivo, a saber, impedir el retorno al país de ciertas categorías de extranjeros que han sido deportados de manera coactiva o de manera voluntaria, mediante una prohibición con un plazo extenso o indefinido ${ }^{57}$.

Su justificación estaría en un enfoque reduccionista de la migración y del retorno, la que obedece a una lógica del apartamiento, contraria a la hospitalidad entendida como un derecho al trato entre seres humanos, derecho que cualquier Estado moderno y democrático debería respetar.

En suma, dado que el PHRO tiene las mismas consecuencias jurídicas que los regímenes administrativo y penal, el PHRO sería una expulsión velada, ya que comparte los mismos efectos que los regímenes administrativo y penal, pero sin el control de la efectiva protección de los Derechos Humanos que ofrecen los tribunales. Como sus efectos son semejantes, se desdibujaría aún más su carácter de plan de retorno del PHRO, a lo que se suma los cuestionamientos a su voluntariedad, atendiendo a las condiciones en las que los migrantes que se acogen a él prestan su consentimiento. Por último, la naturaleza del PHRO como plan de retorno se ve trastocada, en la medida en que pueden acogerse a él quienes, incluso, poseen el estatus de refugiado o hayan solicitado dicha protección.

57 Esta realidad no mejora en el actual proyecto de Ley de Migraciones y Extranjería, Boletín N8.970-06 (4 de junio de 2013), que se discute en el parlamento. Si bien suprime parcialmente el régimen penal de expulsión: deroga delitos especiales del Decreto Ley №1.094, el régimen penal sigue vigente en el caso del delito de usura y como pena sustitutiva. En este sentido, el proyecto colapsa los delitos especiales de los artículos 68 y 69 del Decreto Ley №1094 en el régimen administrativo, estableciéndolos solo como prohibiciones imperativas de ingreso. Además, agudiza la lógica del apartamiento, en la medida que mantiene la prohibición de regreso indefinida y establece la reconducción y reembarco o devolución inmediata de extranjeros. 


\section{Referencias bibliográficas}

Bassa, J. y Torres, F. (2015). Desafíos para el ordenamiento jurídico chileno ante el crecimiento sostenido de los flujos migratorios. Estudios Constitucionales, 13(2), 103-124.

Bix, B. (2006). Teoría del Derecho: tipos y propósitos, Isonomía, (25), 57-68.

Brandariz, J., Dufraix, R. y Quinteros, D. (2018). La expulsión judicial en el sistema penal chileno: ¿Hacia un modelo de Crimmigration?. Política criminal, 13(26), 739-770.

Cancino Ávila, S. (17 de octubre 2018). ¿Deportación disfrazada? Comienza a regir el Plan Humanitario de Regreso Ordenado. Radio JGM Universidad de Chile. Recuperado de https://radiojgm.uchile.cl/deportacion-disfrazada-plan-humanitariode-regreso-ordenado/

Carrasco, I. y Parra, R. (2019). La expulsión de extranjeros: una revisión actual y futura a la luz del debido proceso administrativo sancionador. En Charney, J. (ed.), Derecho y Migración. Actas de las XLVII Jornadas Chilenas de Derecho Público (pp. 333-352). Valparaíso: Ediciones Universitarias de Valparaíso.

Código Penal de la República de Chile. (1874).

Comité de Derechos Humanos de Naciones Unidas. (02 de noviembre de 1999). Observación General №27 "Libertad de circulación (art. 12)”.

Comité de protección de los derechos de todos los trabajadores migratorios y de sus familiares. (28 de agosto de 2013). Observación General №2 “Sobre los derechos de los trabajadores migratorios en situación irregular y de sus familiares".

Constitución Política de la República de Chile. (1980).

Convención Americana sobre Derecho Humanos, San José, Costa Rica (7 al 22 de noviembre de 1969).

Convención internacional sobre la protección de los derechos de todos los trabajadores migratorios y de sus familiares, Nueva York (18 de diciembre de 1990).

Convenciones de Ginebra: Primera, para aliviar la suerte de la condición de los heridos de los ejércitos en campaña, Ginebra, Suiza (1864, 1906, 1929 y 1949); Segunda, para el mejoramiento de la suerte de los militares heridos, enfermos o náufragos en las fuerzas armadas en el mar, Ginebra, Suiza (1906, 1929 y 1949); Tercera, para mejorar la suerte de los heridos y enfermos de los ejércitos en campaña y el relativo al trato de los prisioneros de guerra, Ginebra, Suiza (1929 y 1949); Cuarta, para la protección de personas civiles en tiempo de guerra, Ginebra, Suiza (1949).

Cordero Quinzacara, E. (2012). El derecho administrativo sancionador y su relación con el derecho penal. Revista de derecho, 25(2), 131-157.

Cordero Quinzacara, E. (2013). Concepto y naturaleza de las sanciones administrativas en la doctrina y jurisprudencia chilena. Revista de Derecho Universidad Católica del Norte, 20(1), 79-103. 
Cordero Quinzacara, E. (2014). Los principios que rigen la potestad sancionadora de la Administración en el derecho chileno. Revista de Derecho de la Pontificia Universidad Católica de Valparaíso, 42, 399-439.

Corte Interamericana de Derechos Humanos. (17 de septiembre de 2003). Opinión Consultiva OC-18/03 "Sobre la condición jurídica y derechos de los migrantes indocumentados".

Cruz, J.F. (2018). ¿Cómo aplica la Corte Suprema la legislación migratoria? (Serie Informe Justicia). Instituto Libertad y Desarrollo. Recuperado de https://lyd.org/ wp-content/uploads/2018/10/SIJ-18-C\%C3\%B3mo-aplica-la-Corte-Supremala-legislaci\%C3\%B3n-migratoria-agosto2018.pdf

Chile. Cámara de Diputados. (04 de junio de 2013). Boletín N8.970-06 Proyecto “Ley de Migración y Extranjería".

Chile. Cámara de Diputados. (23 de agosto de 2017). Boletín №11.395-06 Proyecto "Nueva Ley de Migraciones".

Chile. Contraloría General de la República. (7 de octubre de 2011). Dictamen 063697N11 "Sobre cargos formulados por la Superintendencia de Electricidady Combustibles a las empresas Transelec S.A., Transelec Norte S.A. y Chilectra S.A., por la interrupción del servicio de energía eléctrica del Sistema Interconectado Central, ocurrida el 14 de marzo de 2010".

Chile. Contraloría General de la República. (28 de febrero de 2013). Dictamen 013790N13 “Sobre la juridicidad de lo resuelto por el Instituto de Salud Pública de Chile en un sumario instruido en contra de Laboratorio Pasteur S.A.".

Chile. Contraloría General de la República. (09 de abril de 2014). Dictamen 025128N14 "Sobre el plazo de duración de la medida de expulsión del territorio nacional dispuesta por la autoridad administrativa".

Chile. Contraloría General de la República. (13 de mayo de 2016), Dictamen 035511N16 "Sobre la medida que dispone la expulsión de extranjero del territorio del país".

Chile. Corte de Apelaciones de Antofagasta. (3 de abril de 2019). Instituto Nacional de Derechos Humanos con Departamento de Extranjería y Migración. Sentencia en causa Rol №40-219 (acción constitucional de amparo).

Chile. Corte de Apelaciones de Santiago. (3 de enero de 2019). Haitianos con Ubilla (2019). Rol №80259-2018 (acción constitucional de protección).

Chile. Corte Suprema. (6 de marzo de 2014). Compañía Minera Zaldívar Limitada con Secretaria Regional Ministerial de Salud. Rol №7558-2013 (casación en la forma y el fondo).

Chile. Corte Suprema. (7 de marzo de 2017). Ayda Riascos Asprilla con Intendencia regional de Los Lagos. Rol №7007-2017 (apelación de amparo).

Chile. Corte Suprema. (10 de abril de 2017). Leonarda Pujols Rosario con Intendencia de la Región de Arica y Parinacota. Rol №11650-2017 (apelación de amparo). 
Chile. Corte Suprema. (3 de mayo de 2017). Reilly con Ministerio del Interior y otro. Rol №68862-2016 (acción constitucional de protección).

Chile. Corte Suprema. (22 de mayo de 2017). Marlenay Moreno de la Cruz con Intendencia de Arica y Parinacota. Rol №19144-2017 (apelación de amparo).

Chile. Corte Suprema. (21 de agosto de 2017). Juana Geraldo Domínguez contra Intendencia Regional de Arica y Parinacota. Rol №37160-2017 (apelación amparo).

Chile. Corte Suprema. (4 de septiembre de 2017). Marisol Marte Rodríguez con Intendencia Regional de Arica y Parinacota. Rol №38057-2017 (apelación amparo).

Chile. Corte Suprema. (15 de abril de 2019). Rivera Constanza y otros (INDH) con Departamento de Extranjería y Migración del Ministerio del Interior y Seguridad Pública y otro. Rol №9216-2019 (apelación de amparo).

Chile. Corte Suprema. (15 de abril de 2019). Leidy Gálvez Ospina con Ministerio del Interior y Seguridad Pública. Rol №9217-2019 (apelación amparo).

Chile. Ley №18.216 (14 de mayo de 1983), Establece penas que indica como sustitutivas a las penas privativas o restrictivas de libertad.

Chile. Ley №18.415 (14 de junio de 1985), Ley Orgánica Constitucional de los estados de excepción.

Chile. Ley №20.603 (27 de junio de 2012), Modifica la ley №18.216, que establece medidas alternativas a las penas privativas o restrictivas de libertad.

Chile. Ministerio de Hacienda. (27 abril de 1953). Decreto con fuerza de ley $\mathrm{N}^{\circ} 69$, Que crea el Departamento de Inmigración y establece normas sobre la materia.

Chile. Ministerio del Interior. (19 de julio 1975). Decreto Ley №1094, Establece normas sobre extranjeros en Chile.

Chile. Ministerio del Interior. (24 de noviembre de 1984). Decreto supremo №597, Aprueba nuevo reglamento de extranjería.

Chile. Ministerio del Interior. (11 de julio de 2014). Decreto №1393, Crea Consejo de Política Migratoria.

Chile. Ministerio del Interior. (27 de enero de 2015). Decreto №108, Ministerio del Interior, Crea Consejo Técnico de Política Migratoria.

Chile. Ministerio del Interior y Seguridad Pública y la Subsecretaría del Interior. (26 de octubre de 2018). Resolución Exenta №5744, Dispone plan humanitario de regreso ordenado al país de origen de ciudadanos extranjeros.

Chile. Tribunal Constitucional chileno. (26 de agosto de 1996). Control de constitucionalidad del proyecto de ley que modifica la Ley No4.601, Ley de Caza, a fin de proteger la fauna. Rol N²44-96.

Chile. Tribunal Constitucional chileno. (8 de agosto de 2006). Requerimiento de inaplicabilidad por inconstitucionalidad de Compañía Eléctrica San Isidro S.A. y otras respecto del artículo 15 de la ley №18.410, Orgánica de la Superintendencia de 
Electricidad y Combustibles, en autos sobre recursos de reclamación de ilegalidad que indica, de los que conoce la Corte de Apelaciones de Santiago: Rol N479-06.

Chile. Tribunal Constitucional chileno. (21 de octubre de 2010). Requerimiento de inaplicabilidad por inconstitucionalidad de don Hernán Pfeifer Frenz y otros respecto del artículo 169 del Código Sanitario, en la causa Rol №3.073-2009 sobre recurso de amparo preventivo interpuesto en contra del Instituto de Salud Pública ante la Corte de Apelaciones de Santiago caratulado Pfeifer Frenz y otros contra Instituto de Salud Pública. Rol №1518-09-INA.

Chile. Tribunal Constitucional chileno. (4 de julio de 2013). Requerimiento de inaplicabilidad por inconstitucionalidad del ciudadano haitiano Daniel Alerte respecto de los artículos $13,64, N^{\circ} 2^{\circ}$, y 67 , inciso segundo, del Decreto Ley $N^{\circ} 1.094$, en la causa Rol $N^{\circ} 21751-2012$ sobre recurso de protección, seguida ante la Corte de Apelaciones de Santiago caratulada Alerte con Subsecretario del Interior y otros. Rol №. 2273-12-INA

Chile. Tribunal Constitucional chileno. (10 de septiembre de 2013). Requerimiento de inaplicabilidad por inconstitucionalidad de la ciudadana haitiana Sonia Fortilus respecto de los artículos $13,64, N^{\circ} 2^{\circ}$, y 67, inciso segundo, del Decreto Ley $N^{\circ} 1.094$, en la causa Rol $N^{\circ} 6118-2012$ sobre recurso de protección, seguida ante la Corte de Apelaciones de Santiago caratulada Fortilus con Ministro del Interior y otros. Rol №2257-12-INA.

Departamento de Estudios y Proyectos. Defensoría Penal Pública. (2014). Guía Básica. Derecho de las personas extranjeras y migrantes ante el sistema penal. Recuperado de http://www.biblio.dpp.cl/biblio/DataFiles/12253.pdf

Departamento de Extranjería y Migración (DEM). (2016). Primer Boletín informativo. Migración haitiana en Chile. Recuperado de https://www.extranjeria.gob.cl/ media/2016/09/boletin-1.pdf

Díaz, R. (2016). Ingreso y permanencia de las personas migrantes en Chile: Compatibilidad de la normativa chilena con los estándares internacionales. Estudios Constitucionales, 14(1) 179-220.

Domenech, E. (2017). Las políticas de migración en Sudamérica: elementos para el análisis crítico del control migratorio y fronterizo. Terceiro Milênio: Revista Crítica de Sociologia e Política, 8(1), 19-48.

Domenech, E. (2018). Gobernabilidad migratoria: producción y circulación de una categoría de intervención política. Temas de Antropología y Migración, (10), 83-128.

Jarufe, J.P. (2019). El fenómeno migratorio: Evolución legislativa nacional, experiencia comparada y principales puntos de conflicto en la actual discusión legislativa. Asesoría Parlamentaria, Biblioteca del Congreso Nacional. Recuperado en: https://www.senado.cl/appsenado/index.php?mo=tramitacion\&ac=getDocto \&iddocto $=6088 \&$ tipodoc $=$ docto_comision

Enteiche, N. (2014). Sobre el estatuto penal aplicable a las sanciones administrativas en Chile. Revista Actualidad Jurídica, (30), 293-303. 
Fernández, C. y Brandariz, J. (2016). Transformaciones de la penalidad migratoria en el contexto de la crisis económica: El giro gerencial del dispositivo de deportación. InDret. Revista para el análisis del derecho, (4), 2-25.

Galdámez, L. (2013). Comentario jurisprudencial sobre la sentencia del Tribunal Constitucional Rol №2273-12-INA sobre inaplicabilidad de normas del D.L. №10.094 que establece normas sobre los extranjeros en Chile y las matizaciones de la Rol №2257-12-INA. Estudios Constitucionales, 11 (2), 769-782.

Gobierno de Chile. (8 de abril de 2018). Minuta Reforma Migratoria y Política Nacional de Migraciones y Extranjería (2018). Recuperado de https://cdn.digital.gob.cl/filer_public/b0/09/b0099d94-2ac5-44b9-9421-5f8f37cf4fc5/nueva_ley_de_migracion.pdf

Habermas, J. (1997). La idea kantiana de paz perpetua. Desde la distancia histórica de doscientos años. Isegoría, 16, 61-90.

Historia de la Ley №20.603. (2012). Historia de la Ley. Biblioteca del Congreso Nacional. Recuperado de https://www.bcn.cl/historiadelaley/nc/historia-de-la-ley/4505/

Instituto de Políticas Públicas en Derechos Humanos del MERCOSUR. (2017). Derechos Humanos de personas migrantes. Manual Regional (2017). Recuperado de http:// www.corteidh.or.cr/tablas/r33203.pdf

Instituto Nacional de Estadística (INE). (2018). Características de la inmigración internacional en Chile, Censo 2017. Santiago: INE Chile.

Instituto Nacional de Estadística (INE) y Departamento de Extranjería y Migración (DEM). (2019). Estimación de Personas Extranjeras Residentes en Chile. Presentado en Santiago. Santiago.

Kant, I. (1998). Sobre la paz perpetua (J. Abellán trad.). Madrid, Tecnos.

Kelsen, H. (1982). Teoría pura del derecho (R. Vernengo trad.). México D.F.: UNAM.

Letelier, R. (2017). Garantías penales y sanciones administrativas. Política criminal, 12(24), 622-689.

Loyola, I. y Urbina, M.E. (9 de noviembre de 2018). Radiografía a la ola de mensajes en Twitter que generó el plan de retorno para haitianos. CIPER Chile. Recuperado de https://ciperchile.cl/2018/11/09/radiografia-a-la-ola-de-mensajes-en-twitterque-genero-el-plan-de-retorno-para-haitianos/

Maldonado, F. (2015). Efectos del cumplimiento de la condena precedente en el acceso al régimen de penas sustitutivas previstas en la ley 18.216. Consideraciones sobre el estatuto aplicable a la reiteración delictiva, al margen de la agravante de reincidencia. Revista de Derecho Universidad Católica del Norte, 22(2), 243-277.

Martínez, J. y Orrego, C. (2016). Nuevas tendencias y dinámicas migratorias en América Latina y el Caribe. Santiago: CEPAL.

Mónico, C. y Smith Rotabi, K. (2014). International Aid, Relief, and Humanitarian Assistance. Encyclopedia of Social Work. Recuperado de http://oxfordre. com/socialwork/view/10.1093/acrefore/9780199975839.001.0001/acrefore-9780199975839-e-957 
Muñoz Ruiz, J. (2014). La expulsión penal. Nuevas tendencias legislativas. Revista Electrónica de Ciencia Penal y Criminología, 16-05, 05:1-05:44. Recuperado de http://criminet.ugr.es/recpc/16/recpc16-05.pdf

Organización Internacional para las Migraciones (OIM). (2018). A framework for assisted voluntary return and reintegration. Recuperado de https://www.iom.int/ sites/default/files/our_work/DMM/AVRR/a_framework_for_avrr_online_pdf_optimized_20181112.pdf

Pacto internacional de derechos civiles y políticos, Nueva York (16 de marzo de 1966).

Parlamento Europeo y del Consejo. (23 de mayo de 2007). Decisión N575/2007/CE “Por la que se establece el Fondo Europeo para el Retorno para el período 2008-2013 como parte del Programa general «Solidaridad y Gestión de los Flujos Migratorios»".

Meza-Lopehandía, M. (2014). Regulación de la Migración en Chile y España. Asesoría Parlamentaria, Biblioteca del Congreso Nacional, 2014 (n base a trabajos de Finsterbusch, C. y Cifuentes, P). Recuperado de https://www.bcn.cl/obtienearchivo?id=repositorio/10221/20215/5/FINAL\%20_\%20Meza_Lopehandia\%20 _\%20Finsterbusch\%20y\%20Cifuentes\%20_\%20Regulacion\%20de\%20la\%20 migracion\%20en\%20Chile\%20y\%20Espana_v2.pdf

Resino, R., Jiménez, B. y Arranz, M. (2018). Retorno migratorio desde España: un flujo variable y complejo. Migraciones, (44), 91-118. DOI: mig.i44.y2018.004

Revista Colecciones Jurídicas: “Migrantes”. (2019). Dirección de Estudios de la Corte Suprema. Revista Colecciones Jurídicas: “Migrantes". Recuperado de http://decs.pjud. cl/migrantes-nueva-publicacion-sobre-colecciones-juridicas-de-la-corte-suprema/

Salinero, S. (2011). La expulsión de extranjeros en el derecho penal. Una realidad en España, una posibilidad en Chile. Política criminal, 6(11), 106-141.

Salinero, S. (2012). Recensión: TORRES FERNÁNDEZ, María Elena, La expulsión de extranjeros en el Derecho penal, Madrid: La Ley, 2012, 322 páginas. Política Criminal, 7(14), 489-491.

Sánchez, C. y Fernández, B. (2010). Retorno voluntario de migrantes. Trabajo. Revista iberoamericana de relaciones laborales, (23), 138-139.

Sayad, A. (1999). Immigration et 'pensée d'État'. Actes de la recherche en sciences sociales, 129, 5-14. DOI: https://doi.org/10.3406/arss.1999.3299

Stang, F., Lara, A. y Andrade, M. (2019). Retórica humanitaria y expulsabilidad: migrantes haitianos y gobernabilidad migratoria en Chile [Inédito].

Stumpf, J. (2006). The Crimmigration Crisis: Immigrants, Crime, and Sovereign Power. American University Law Review, 56(2), 367-419.

Sunstein, C. (1995). On Legal Theory and Legal Practice. Nomos, 37, 267-287.

Victor Condé, H. (2004). A Handbook of International Human Rights Terminology. Lincoln and London: University of Nebraska Press. 